\title{
Opinióes de docentes e de coordenadores acerca do fenômeno da evasão discente dos cursos de graduação da Universidade Federal do Ceará (UFC)
}

Wagner Bandeira Andriola

Cristiany Gomes Andriola

Cristiane Pascoal Moura

\section{Resumo}

O texto aborda o fenômeno da evasão discente em cursos de graduação da Universidade Federal do Ceará - UFC, desde a perspectiva de docentes e de coordenadores. Após revisão da literatura e apresentação das investigações executadas por W. B. Andriola e colaboradores, são descritos dados obtidos com 52 docentes e 21 coordenadores de cursos de graduação da UFC. Os resultados atestam que a maioria dos coordenadores e dos docentes entrevistados tem opinião favorável ao resgate da função do professor orientador. Opinam também que cabe às coordenações fornecer informações pertinentes e relevantes a todos os potenciais candidatos aos cursos de graduação da UFC. Por fim, acrescentam que caberá ao gestor dar ênfase à melhoria da infra-estrutura física, com especial atenção às salas de aula e aos laboratórios.
Palavras-chave: Educação superior. Evasão discente. Avaliação institucional.

\section{Resumen}

Opiniones de docentes y

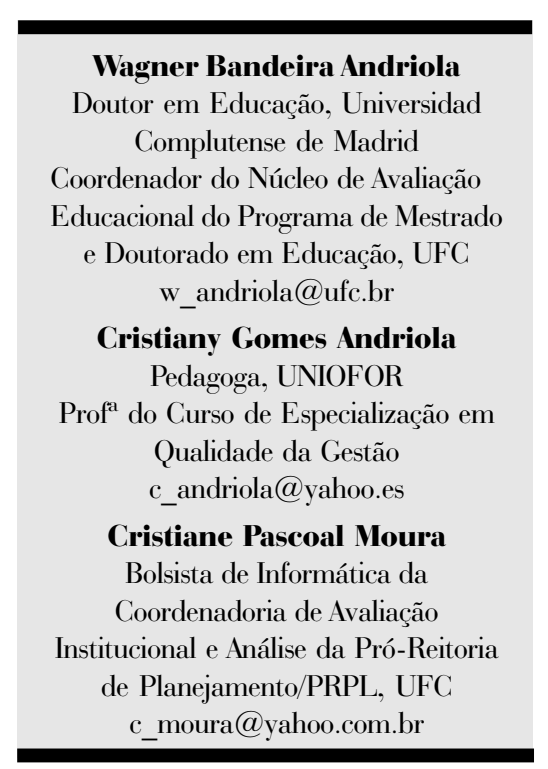

de coordinadores de cursos sobre el fenomeno de la deserción discente de los cursos de graduación de la Universidad Federal de Ceará (UFC)

El texto aborda el fenómeno de la deserción discente de cursos de graduación de la Universidad Federal de Ceará (UFC), según la óptica de los docentes y de los coordinadores. Después de una breve revisión de la 
literatura y de la presentación de investigaciones llevadas a cabo por W.

B. Andriola y colaboradores, son descriptos datos obtenidos con 52 docentes y 21 coordinadores de cursos de graduación de la UFC. Los resultados atestan que la mayoría de los coordinadores y de los docentes entrevistados tienen la opinión favorable al rescate de la función del profesor orientador. También creen que cabe a las coordinaciones fornecer informaciones pertinentes y relevantes a todos los potenciales candidatos a los cursos de graduación de la UFC.

Finalmente, añaden que tocará al gestor dar relieve a la mejoría de la infraestructura física, con especial atención a las clases y a los laboratorios.

Palabras clave: Educación superior.

Deserción discente. Evaluación institucional.

\section{Abstract \\ The opinions of teachers and coordinators concerning the phenomenon of student desistence from courses at graduate at the Federal University of Ceará (UFC)}

This research studies the phenomenon of students desistence from courses at graduate level at the Federal University of Ceará - UFC, from the teachers and coordinators perspectives. Having made a revision of the literature available on the matter and the investigations carried out by W. B. Andriola and his assistents, this text offers data from 52 teachers and 21 coordinators of courses at graduate level at the UFC. The results show that the majority of the coordinators and the teachers who were interviewed had a favorable opinion for the function of a teacher tutor. They were also of the opinion that the coordinators are responsible to offer relevant and pertinent information to all candidates for graduate courses at the UFC. Finally, they felt that it up to the administrator to improve the physical infrastructure with special attention to the classrooms and the laboratories.

Keywords: Higher education. School desistence. Institutional assessment.

\section{Introdução}

Os modelos teóricos para explicar as causas da evasão discente, desenvolvidos por Tinto $(1975,1987)$ e posteriormente aprimorado por Bean (1980, 1983), destacam-se por serem bastante utilizados nas universidades norteamericanas, bem como em outros países tais como México, Austrália e Reino Unido. Tinto $(1975,1987)$ sugere que o estudante deixa a universidade por problemas causados pela falta de integração com o ambiente acadêmico e social da instituição. De acordo com o modelo, essa integração é influenciada, direta ou indiretamente, por características demográficas do discente, tais como: nível socioeconômico da família, expectativa dos pais a respeito do futuro do filho, habilidades acadêmicas do aprendiz, conhecimentos adquiridos através da educação formal e/ou informal, além de características individuais como gênero e raça (UNESCO, 1997).

Na opinião de Tinto (1975, 1987), o aluno chega à universidade com intenções, objetivos e compromissos institucionais prédefinidos, que variam em função das características demográficas supra-menciona- 
das. Com o tempo, o aluno passa por uma série de interações com o ambiente acadêmico e social da instituição educacional, o que lhe permite, assim, redefinir suas intenções e seus compromissos, o que, em última instância, leva-o a persistir ou a evadirse (ANDRIOLA, 1997b).

Nesse sentido, Gouveia, Albuquerque e Solha (1994, p. 16) asseveram: "As pessoas podem estar formando as suas expectativas sem uma base real, o que lhes permite, ao ingressar e se depararem com tal instituição, ter decepções e frustrações ao perceberem outra realidade".

Col Debella (1978) encontrou dados que se ajustam à opinião de Gouveia, Albuquerque e Solha (1994), pois, de acordo com o mesmo, já no primeiro semestre de estudos, começa a caracterizar-se a frustração dos universitários com a instituição. Para Morais (1995), é esse fenômeno que caracteriza a estranha relação de atração e ao mesmo tempo de rejeição, existente entre o meio social e as universidades, sobretudo as públicas.

Ademais, o modelo desenvolvido por Bean $(1980,1985)$ supõe que a decisão de eva- dir-se ou de persistir no curso é um processo psicossocial, no qual as opiniões influenciam as atitudes e estas, por seu turno, influenciam as decisões. Sendo assim, a permanência ou a evasão do estudante é função das suas atitudes, da sua adaptação à universidade, e de fatores externos, como por exemplo: aprovação da família, encorajamento dos amigos, qualidade da instituição, situação financeira e oportunidade para transferir-se para outra instituição (ANDRIOLA; RIBEIRO; MOURA, 2005).

modelo de Tinto (1975) afirma que a decisão de evadir-se é tomada em função da integração social e acadêmica, desenvolvida na universidade. Essa integração, por sua vez, é influenciada por características individuais, pelas expectativas para a carreira ou curso e, por último, pelas intenções/objetivos e compromissos assumidos no período pré-universitário. Porém, o modelo, tal como foi proposto, não se aplica, na sua totalidade, à realidade brasileira, pois desconsidera dois importantes aspectos: as peculiaridades dos cursos de graduação e a influência de fatores externos à vida acadêmica (contexto social e institucional). A representação do modelo proposto por Tinto (1975) encontra-se na Figura 1, apresentada em seguida.

\section{Figura 1. Modelo explicativo da evasão discente proposto por Tinto (1975).}

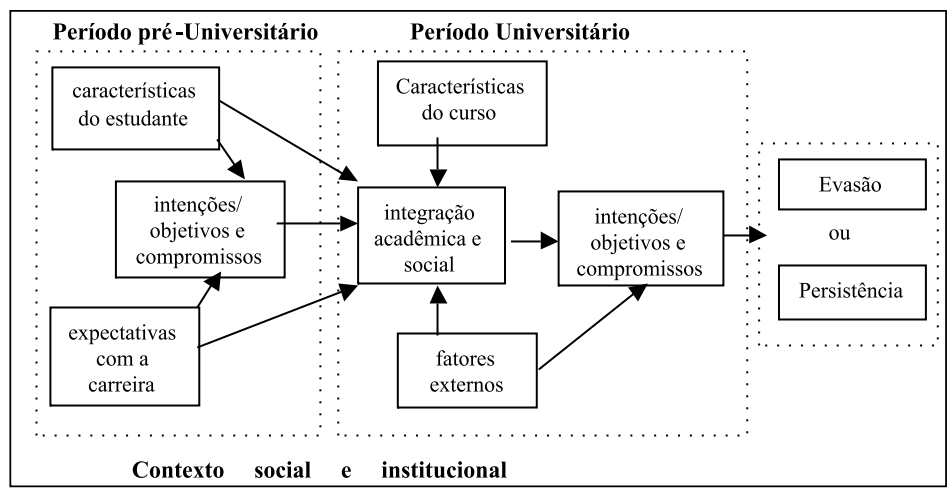


Assim, assumindo-se que os cursos das universidades brasileiras variam substancialmente entre as áreas e até mesmo dentro da mesma instituição (BRASIL, 1996) poderão ser incorporadas variáveis relacionadas aos cursos de graduação, como uma forma de determinar o seu impacto sobre a evasão (STOECKER; PASCARELLA; WOLFLE, 1988). Assumindo-se também, que alguns fatores externos exercem um certo grau de influência sobre a performance acadêmica do estudante (BEAN; METZNER, 1985), e sobre o processo de integração social, algumas variáveis que medem essa influência também poderão vir a ser incluídas no modelo.

Muito embora Tinto (1975, 1987) e Bean $(1980,1983)$ tenham concebido a evasão discente sob diferentes perspectivas, Nora, Castaneda e Cabrera (1992) mostraram que uma metodologia integrando aspectos de ambos os modelos pode aumentar a compreensão acerca desse fenômeno educacional. Esse modelo alternativo comprovou que se obtém melhor compreensão acerca da evasão discente quando aspectos individuais, institucionais e externos à instituição superior foram combinados.

\section{Dados da evasão discente nos cursos de graduação da Universidade Federal do Ceará}

Os dados acerca da evasão discente no ensino superior são pouco explorados, acarretando, consequentemente, diminuta compreensão do fenômeno e de suas causas. Por exemplo, informes da Universidade Federal da Bahia (UFBA)' ${ }^{\prime}$, demonstram que as taxas de evasão na graduação, nos anos 2000 e 2001 , foram $9,1 \%$ e $7,2 \%$, respectivamente. No âmbito da Universidade Federal do Ceará (UFC) esta taxa está ao redor de 5,74\% ao ano, conforme atestam Andriola, Ribeiro e Moura (2005). Tal percentual corresponde a aproximadamente, 206 casos de abandono, já que a UFC oferece anualmente 3.585 vagas à sociedade. ${ }^{2}$ É um número bastante considerável, iá que, como demonstramos, os elevados índices de evasão representam um ônus adicional à sociedade, pois implica no uso indevido das vagas oferecidas à sociedade, já tão escassas, e no desperdício financeiro de verbas públicas, além de atestarem certa incapacidade da gestão no trato do problema (AMARAL, 1999; RIBEIRO; MOURA; ANDRIOLA, 2003).

Nesse contexto, Cláudio de Moura Cas-
tro ([200-?] $])^{3}$ asseverou:
Com um sistema educacional tão fraco,
é difícil entender como o Brasil conse-
guiu crescer em ritmo tão acelerado.
Entre 1930 e 1993 a economia do Bra-
sil cresceu (em termos absolutos) mais
depressa que a do Japão ou da Coréia,
países geralmente dados como exem-
plo de progresso econômico.

Destaque-se, ademais: são tão poucos aqueles que chegam ao ensino superior, entre $9 \%$ e $12 \%$ da população jovem (18 a 24 anos), que não podemos permitir as desistências ou os abandonos (DURHAM, 1998; PACHECO; RISTOFF, 2004). Essa constatação justificou o estudo conduzido pela Comissão Especial de Estudos acerca da Evasão nas Universidades Públicas Brasileiras, instituída em 1995, pela Secretaria da Educação Superior do Ministério de Educação e Desportos (BRASIL, 1996).

\footnotetext{
${ }^{1}$ http://www.proplad.ufba.br/indicadores2000-2001.html

2 Dado referente ao vestibular de 2000 (UNIVERSIDADE FEDERAL DO CEARÁ, 1999).

${ }^{3}$ Disponível em: <http://www.mre.gov.br/cdbrasil/itamaraty/web/port/polsoc/educa/apresent/apresent.htm>.
} 


\section{Estudos efetivados por W. B. Andriola e colaboradores}

No âmbito interno da UFC, W. B. Andriola e colaboradores vêm desenvolvendo, desde o início do ano acadêmico de 2003, estudos sistemáticos acerca do fenômeno da evasão discente. Dentre o grupo de colaboradores destacam-se: discentes da graduação em Pedagogia; mestrandos e doutorandos do programa de pós-graduação em Educação, além de docentes do Núcleo de Avaliação Educacional (NAVE) do mesmo programa. No tópico a seguir as investigações executadas ou em execução serão esmiuçadas.

\section{Busca das causas da evasão discente, segundo os próprios evadidos}

A primeira dessas investigações foi levada a cabo em 2003 por Andriola, Ribeiro e Moura (2003) e teve como objetivo conhecer as opiniões dos evadidos dos cursos de graduação acerca dos motivos ou das causas que os impeliram a tal. A população desse primeiro estudo compunha-se de evadidos dos cursos de graduação da UFC $(N=412)^{4}$, entre os anos 1999 e 2000, sendo a amostra formada por 86 universitários evadidos do período mencionado, o que correspondeu a $21 \%$ de alunos dessa população estudantil. A respeito das características demográficas da amostra, interessa-nos ressaltar que $68,2 \%$ dos entrevistados eram mulheres ( $n=59$ ) e $85,9 \%$ eram solteiros $^{5}(n=74)$, com idade média de 26,36 anos (desvio-padrão 6,50 anos). Cerca de $90 \%$ dos evadidos $(n=77)$ ingressaram na
UFC através do processo seletivo conhecido pelo nome de "Vestibular", sendo que 74,1\% dos evadidos ( $n=63$ ) concluíram o ensino médio em escolas particulares.

Com respeito aos resultados obtidos, comecemos por aclarar que uma das primeiras indagações feitas aos evadidos objetivou identificar os principais motivos responsáveis pela escolha do curso ou da carreira superior. De acordo com 64,2\% dos entrevistados ( $n=55)$, o gosto, o interesse e a afinidade pessoal com a área do curso ou da carreira escolhida foram os fatores que mais pesaram na tomada de decisão. Posteriormente, perguntou-se aos alunos evadidos o nível de conhecimento sobre alguns aspectos relevantes do curso ou da carreira universitária, isto é, se tinham ou não informações sobre o mesmo. Segundo os dados, $40 \%$ dos evadidos $(n=34)$ escolheram seu curso sem ter qualquer tipo de informação sobre o mesmo, ou seja, deixando totalmente ao acaso o acerto na eleição de sua futura profissão.

Indagados sobre os motivos responsáveis pela deserção ou pelo abandono dos cursos ou carreiras universitárias, os evadidos apresentaram os seguintes fatores:

- Incompatibilidade entre horários de trabalho e de estudo (destacado por $39,4 \%$ ou 34 evadidos);

- Aspectos familiares (p. ex.: necessidade de dedicar-se aos filhos menores) e desmotivação com os estudos (justificado por $20 \%$ ou 17 dos evadidos);

- Precariedade das condições físicas do curso ou inadequação curricular (mencionado por $10 \%$ ou nove evadidos).

${ }^{4}$ De acordo com os dados da Pró-Reitoria de Planejamento, em seu Relatório Técnico de 2001 (UNIVERSIDADE FEDERAL DO CEARÁ, 2001).

${ }^{5}$ No início da carreira superior o percentual de solteiros da amostra estudada era de $95,3 \%$. 
Constatam-se a partir desses dados que os motivos de ordem pessoal e institucional são ambos os maiores responsáveis pela deserção acadêmica, no âmbito da UFC. Estes fatores podem explicar por que $21,2 \%$ dos evadidos ( $n=18$ ) estavam cursando novas carreiras universitárias em instituições de ensino superior distintas da UFC, no momento da realização da investigação.

Agora bem indagados acerca do posicionamento familiar após o abandono ter sido efetivado, $32,9 \%$ dos evadidos ( $n=28$ ) afirmaram que seus familiares não aprovaram a desistência do curso ou da carreira profissional, sendo que em $23,5 \%$ dos casos ( $n=20$ ), não houve qualquer posicionamento dos familiares. Finalmente, segundo $43,5 \%$ dos universitários ( $n=37$ ), seus familiares lhes apoiaram na decisão de abandonar seus respectivos cursos ou carreiras universitárias.

Os alunos desertores foram indagados acerca da satisfação com o abandono do curso superior escolhido anteriormente. A maioria afirmou estar satisfeita com o abandono ( $n=59$ ou $68,2 \%$ dos abordados); por outro lado, 30,8\% dos universitários evadidos afirmaram estar insatisfeitos com a decisão do abandono ( $n=27)$.

\section{Testagem de modelo causal}

Posteriormente, ainda de posse dos dados obtidos com os 86 discentes evadidos, procedeu-se ao teste de um modelo causal explicativo da intenção de voltar a cursar outro curso superior. Desse modo, Andriola e Ribeiro (2005) utilizaram o modelo da análise de regressão linear múltipla para tentar predizer a variável dependente "( $Y$ ) intenção de voltar a cursar outra carreira superior" a partir das variáveis independentes: (a) "satisfação com o abandono", (b) "grau de informação acerca do curso universitário", (c) "contribuição econômica familiar" e (d) "opiniões acerca das limitações do curso abandonado". Inicialmente, verificamos a plausibilidade do modelo proposto, utilizando o teste da análise de variância (ANOVA), conforme demonstram os resultados presentes no Quadro 1.

\section{Quadro 1. Resultados do uso do teste ANOVA.}

\begin{tabular}{|c|c|c|c|c|c|}
\hline $\begin{array}{c}\text { Modelo } \\
\text { proposto }\end{array}$ & $\begin{array}{c}\text { Soma de } \\
\text { quadrados }\end{array}$ & $\begin{array}{c}\text { Graus de } \\
\text { liberdade }\end{array}$ & $\begin{array}{c}\text { Quadrados } \\
\text { médios }\end{array}$ & F & P \\
\hline Regressão & 2,449 & 4 & 0,612 & 6,207 & 0,000 \\
Residual & 5,130 & 52 & 0,099 & & \\
Total & 7,579 & 56 & & & \\
\hline
\end{tabular}

Os resultados do teste ANOVA confirmam que o modelo proposto é factível para explicar a variável dependente "(Y) intenção de voltar a cursar outra carreira superior" a partir das variáveis independentes (a), (b), (c) e (d), explicitadas anteriormente. Num segundo momento utilizamos, efetivamente, o modelo da análise de regressão linear múltipla, através do método ENTER, que supõe a adoção de algumas hipóteses estabelecidas a priori para explicar a variável dependente.

A principal dessas conjecturas fundamenta-se na premissa de que o grau de informação dos discentes acerca do curso superior e da própria instituição educacional é fator ou 
variável relevante à compreensão da intenção de voltar a cursar outra carreira superior. Esse mesmo aspecto influencia de modo contundente um fator secundário, qual seja: as percepções e as opiniões discentes acerca das limitações e das potencialidades do curso superior escolhido. Ambos os fatores até aqui explicitados influenciarão, por seu turno, uma terceira variável: a satisfação com o abandono. Este terceiro elemento explicativo de- verá ter elevada associação com a última das variáveis propostas para o modelo causal, qual seja: a contribuição econômica familiar com os gastos derivados do ato de cursar uma carreira acadêmica.

Os resultados do uso do modelo da análise de regressão linear múltipla, através do método ENTER, são apresentados no Quadro 2.

Quadro 2. Resultados do uso da análise de regressão linear múltipla.

\begin{tabular}{|c|c|c|c|c|c|}
\hline \multirow[t]{2}{*}{$\begin{array}{c}\text { Variáveis } \\
\text { Independentes }\end{array}$} & \multicolumn{2}{|c|}{$\begin{array}{c}\text { Coeficientes não } \\
\text { padronizados }\end{array}$} & \multirow{2}{*}{$\begin{array}{c}\text { Coeficientes } \\
\text { padronizados } \\
\text { Beta }\end{array}$} & \multirow{2}{*}{$t$} & \multirow{2}{*}{$\mathrm{p}$} \\
\hline & Beta & Erro padrão & & & \\
\hline (a) & $-0,199$ & 0,091 & $-0,260$ & $-2,175$ & 0,034 \\
\hline (b) & 0,258 & 0,087 & 0,347 & 2,963 & 0,005 \\
\hline (c) & $-0,261$ & 0,092 & $-0,333$ & $-2,851$ & 0,006 \\
\hline (d) & $-0,137$ & 0,001 & $-0,208$ & $-1,768$ & 0,083 \\
\hline Constante & 2,259 & 0,253 & - & 8,935 & 0,000 \\
\hline
\end{tabular}

De acordo com os dados apresentados no Quadro 2, observamos que três variáveis independentes (a), (b) e (c) são relevantes para explicar a variável dependente $(Y)$ "intenção de voltar a cursar outra carreira superior", pois obtiveram resultados estatisticamente signi- ficativos $(p<0,05)$. A variável independente (d) foi mantida no modelo porque tem tendência à significação estatística ( $p<0,09)$, em conformidade com a opinião de Puente Viedma (1993). Os resultados sintetizados do modelo linear são apresentados no Quadro 3.

\section{Quadro 3. Sumário dos resultados para o modelo proposto.}

\begin{tabular}{|c|c|c|c|}
\hline$R$ & $R^{2}$ & $R^{2}$ ajustado & Erro de estimação \\
\hline 0,568 & 0,323 & 0,271 & 0,314 \\
\hline
\end{tabular}

Como podemos observar, o modelo proposto é responsável pela explicação de $27,1 \%$ ( $R^{2}$ ajustado) da variância total dos resultados da variável dependente
(Y) "intenção de voltar a cursar outra carreira superior". Ademais, com estes dados é possível, agora, construir o modelo linear, que é:

$$
Y=2,259+0,258 X b-0,137 X d-0,199 X_{a}-0,261 X_{c}+e(=0 ;=0,314) \text {. }
$$


Note-se que, na equação apresentada, o último termo é o erro de estimação (e), que possui média zero $(=0)$ e desvio-padrão igual ao erro de estimação $(=0,314)$.

Finalmente, a interpretação do modelo, a partir dos valores Beta presentes no Quadro 3, nos permite chegar à seguinte conclusão:

- A variável independente (b) "grau de informação acerca do curso universitário" é a que possui maior valor Beta e, portanto, a que melhor explica a variável dependente $(Y)$.

- A segunda variável independente a compor o modelo foi (d) "opiniões acerca das limitações do curso abandonado".

- A "satisfação com o abandono" foi a terceira variável a compor o modelo, dado o seu valor Beta, menor que as duas anteriormente apresentadas.

- Por fim, a variável independente (c) "contribuição econômica familiar" foi a última a compor o modelo linear, dado o seu menor valor Beta.

A Figura 2, apresentada a seguir, caracteriza o modelo causal explicativo da variável independente "intenção de voltar a cursar outra carreira acadêmica", a partir das quatro variáveis independentes $(a, b, c$, d) já descritas em apartados anteriores.

\section{Figura 2. Modelo causal proposto por W. B. Andriola e colaboradores (2005).}

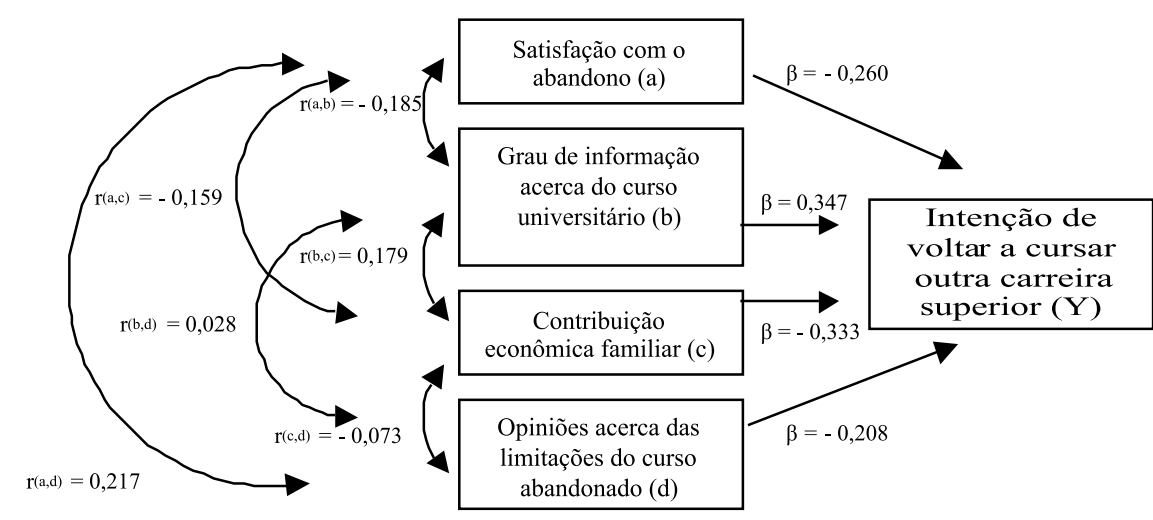

CONTEXTO INSTITUCIONAL: IFES sem política interna institucionalizada de combate à evasão discente; possui aproximadamente 21.000 alunos matriculados em 54 cursos de graduação; anualmente ingressam $20 \%$ de novos alunos oriundos de escolas públicas (700 aprendizes/ano); custo corrente/aluno equivalente: $\mathrm{R} \$ 8.400,00$ $\left(\right.$ dados de 2005) ${ }^{6}$.

CONTEXTO SOCIAL: IFES sediada na cidade de Fortaleza (município com 2.200.000 habitantes); IDH 0,79; Taxa de mortalidade infantil: 24,5 por 1.000 nascidos vivos; Renda per capita: R \$ 5.625,00; Taxa de desemprego 13,6\%; IDH - Educação: 0,88; Taxa de jovens de 18 a 24 anos no Ensino Superior: 7,3\% (dado relativo ao Ceará); Taxa de jovens com mais de 25 anos no Ensino Superior: $11,9 \%$ (dados de 2003).

\footnotetext{
${ }^{6}$ Dados institucionais relativos ao ano 2004. Disponível em: <http://www.ufc.br $>$.
} 
Para a compreensão do modelo causal, acima apresentado, faz-se necessário tão-somente um comentário adicional: os semicírculos representam as associações entre as variáveis independentes, isto é, o grau de correlação existente entre as mesmas. Na sua medida foi empregado o coeficiente de correlação $r$ de Pearson, cujos valores variaram entre -0,185 e 0,217, todos eles não-significativos (isto é: todos os coeficientes $r$ possuem $p>0,05$ ), caracterizando, assim, a ausência de associação entre as 4 variáveis independentes.

\section{Opinião de docentes e de coordenadores acerca da evasão discente}

Conhecendo-se os fatores associados à evasão discente, bem como algumas das variáveis com elevado grau de explicação para a intenção de voltar a cursar outra carreira acadêmica, era o momento, na nossa visão, de sondar os docentes e os coordenadores dos cursos de graduação acerca do mencionado fenômeno socioeducacional.

Sendo assim, a terceira fase da investigação foi iniciada em julho de 2004, através de pesquisa de campo, do tipo ex postfacto, na qual se utilizou amostra formada por 21 coordenadores e 52 docentes das nove unidades acadêmicas da UFC (Centros e Faculdades). A escolha dos sujeitos deu-se de forma não-probabilística, isto é, segundo a disponibilidade dos docentes e dos coordenadores de cursos de graduação, além da facilidade de obtenção dos dados. Utilizou-se um questionário semi-estruturado com 13 indagações abordando os seguintes aspectos: resgate da função do professor orientador; informações necessárias aos futuros universitários acerca do curso escolhido; opinião dos coordenadores acerca do envolvimento docente no ensino de graduação; contribuição da atual administração da UFC para a melhoria do desempenho das coordenações; papel da gestão central, dos coordenadores e dos docentes no combate ao fenômeno da evasão. $\bigcirc$ mencionado instrumento foi aplicado de modo individualizado, após o qual as informações obtidas foram analisadas através do uso da análise de conteúdo, procedimento que consiste em extrair categorias qualitativas das respostas apresentadas pelos entrevistados e observar a freqüência de ocorrência das mesmas.

\section{Opinião dos Coordenadores}

A função do Professor Orientador é prevista no Regimento Geral da Universidade Federal do Ceará (Subtítulo II, que trata dos Órgãos Executivos; Capítulo I; Artigo 28; Alínea d). De acordo com o mesmo, seu papel será, primordialmente, orientar os alunos para evitar as dificuldades de aprendizagem e, assim, diminuir os índices de reprovações, interrupção de matrículas e evasões. A partir dessa definição, analisamos a opinião dos entrevistados acerca da possibilidade de vir a ser resgatada essa relevante função acadêmica e pedagógica. Verificamos que $87 \%$ dos coordenadores foram favoráveis ao resgate da função do professor orientador, entretanto, 20\% apontaram como aspectos primordiais para a implementação dessa atividade:

a) Preparação do corpo docente;

b) Disponibilidade de tempo para tal atividade, formalmente estabelecida enquanto atividade docente;

c) Compromisso formalmente assumi- 
do por todos os docentes visando o acompanhamento direto e sistemático aos discentes.

A desinformação acerca do curso e da carreira superior escolhida é um fator responsável pela evasão discente, conforme verificado empiricamente através do modelo causal testado por W. B. Andriola e Ribeiro (2005). Sendo assim, indagamos aos coordenadores se caberia às coordenações informar melhor aos futuros universitários acerca do curso escolhido e como poderia ser implementada essa atividade. Para $92 \%$ dos entrevistados, é papel das coordenações fornecerem informações necessárias acerca do curso superior, sendo que poderiam ser repassadas aos estudantes através da:

a) Realização de seminários e disciplinas introdutórias (enumerado por $32 \%$ dos coordenadores);

b) Visitas às escolas de ensino médio (destacado por $27 \%$ dos coordenadores);

c) Divulgação de informações pela lnternet e por meio de trabalho coletivo entre as coordenações e as PróReitorias de Graduação e de Assuntos Estudantis (enfatizado por 14\% dos coordenadores).

A opinião dos coordenadores acerca do envolvimento docente com o ensino de graduação ressaltou que o mesmo é insatisfatório para $41,1 \%$ dos entrevistados; é satisfatório para $36,8 \%$ dos coordenadores, embora destaquem que muitos docentes priorizam o ensino de pós-graduação e a pesquisa; é parcialmente satisfatório para 21,01\%.

Indagados acerca de como a atual administração da UFC pode contribuir para melhorar o desempenho das coordenações, foram enumeradas as seguintes ações:

a) Urgência na efetivação de ações visando melhorias na infra-estrutura (destacado por $41,6 \%$ dos coordenadores); b) Importância do apoio da Reitoria e da Pró-Reitoria de Graduação (ressaltado por $25 \%$ dos coordenadores);

c) Necessidade de maior autonomia e poder de decisão (enumerado por $16,6 \%$ dos coordenadores).

Ademais, os coordenadores foram indagados acerca do que a UFC, as coordenações e os docentes poderiam fazer para combater o problema da deserção discente, cuja taxa anual ronda os 5,74\% e que se traduz em 206 novos casos de abandono, pois a UFC oferece anualmente 3.585 vagas à sociedade (ANDRIOLA, 2005; ANDRIOLA, RIBEIRO; MOURA, 2005). Nesse âmbito, 23\% dos coordenadores ressaltaram que seria necessário a UFC darIhes maior apoio às atividades de estágio, monitoria, pesquisa e extensão. Em segundo lugar, foi destacada por 15,3\% dos coordenadores a urgência em melhorar a estrutura física dos cursos, no que diz respeito às salas de aula, laboratórios e recursos áudio-visuais. $\bigcirc$ aumento das ofertas de cursos noturnos e a melhoria da qualidade do ensino e do projeto político-pedagógico foram aspectos ressaltados como imprescindíveis à diminuição da evasão discente, de acordo com 11,5\% dos entrevistados.

Quanto ao modo como as coordenações poderiam executar atividades de apoio e incentivo aos discentes, $45 \%$ dos coordenadores ressaltaram a conversa com os pretensos a abandonar o curso para, assim, tentar reverter a situação. Em seguida, $25 \%$ enfatizaram que é importante a con- 
tribuição das coordenações na melhoria da qualidade do ensino e do projeto políticopedagógico dos cursos. Não obstante, os coordenadores alegaram que para a realização dessas atividades, as coordenações necessitam de maior aporte orçamentário, além da imperiosa necessidade de estreitar parcerias com as Pró-Reitorias de Graduação e de Assuntos Estudantis.

Acerca da atuação docente, 31,8\% dos entrevistados indicaram que é preciso haver maior compromisso por parte destes com o ensino de graduação, visto que, muitos estão mais envolvidos com o ensino da pósgraduação e com pesquisas. Também foi destacado por 18,1\% dos entrevistados que os docentes poderiam orientar e ampliar o incentivo dos discentes para a realização de atividades relevantes à vida acadêmica. Finalmente, foram destacadas por 9\% dos coordenadores as ações acadêmicas para evitar a evasão discente: adequada avaliação do desempenho dos alunos, combate às dificuldades de aprendizagem, meIhoria da didática e melhoria da relação professor-aluno.

A necessidade de trabalhar e a incompatibilidade de horários para estudar foram os dois motivos mais citados pelos evadidos para abandonarem os cursos. Para a resolução desses dois problemas os coordenadores apontaram como saídas:

a) aumento da oferta de bolsas (pesquisa, extensão, assistência e monitoria) e estágios (citado por $28 \%$ dos coordenadores);

b) necessidade de ministrar todas as disciplinas em um só turno, visto que em muitos cursos da UFC são ministradas nos três turnos dificultando a vida dos estudantes que precisam trabalhar ou realizar atividades não acadêmicas (mencionado por $24 \%$ dos entrevistados); c) aumento da oferta de cursos noturnos (destacado por 12\% dos coordenadores).

\section{Opinião dos Docentes}

Igualmente como ressaltado pelos coordenadores, $74 \%$ dos docentes entrevistados são favoráveis ao resgate da função do professor orientador, no âmbito interno da UFC. Dessa população 40,5\% apontaram que o maior benefício seria o acompanhamento direto ao discente durante o seu aprendizado, ajudando-o a evitar as reprovações e, consequentemente, a desmotivação para com os estudos. Entretanto, apesar de serem favoráveis, 16,2\% destacaram que para a realização de um trabalho de orientação contínua são necessárias: a preparação do corpo docente, a disponibilidade de tempo de recursos materiais e, por fim, a atribuição de pontos na Gratificação de Estímulo à Docência (GED).

Embora a maioria dos docentes tenha sido favorável à implementação dessa atividade, $12 \%$ são desfavoráveis e $14 \%$ afirmaram que a realizam ou realizaram-na. Dentre os docentes desfavoráveis, as seguintes justificativas foram apresentadas: número insuficiente de docentes; falta de tempo (afirmaram que já se encontram com muitas atividades, sendo impossível dar conta de mais uma); recursos insuficientes para a realização desse tipo de trabalho. Há aqueles que crêem que o problema dos discentes não está reduzido à aprendizagem, mas sim a vida pessoal. Dessa ótica, portanto, desnecessário faz-se a atuação do professor orientador. Por fim, há também aqueles que acreditam que essa atividade acabaria sendo paternalista e prepararia alunos dependentes e sem iniciativas. 
Dentre o grupo de docentes que conta com algum tipo de experiência como professor orientador, $42,8 \%$ afirmou que a resposta dos discentes à orientação é insatisfatória. Segundo esses docentes poucos discentes comprometem-se com os estudos e muitos deles sequer comparecem às reuniões. Em contrapartida, $28,5 \%$ dos docentes relataram que o processo é muito favorável, visto que o papel do orientador tem ajudado os discentes nas dificuldades de aprendizagem. Ademais, asseguram que conseguiram, com isso, evitar muitas reprovações.

Os docentes também foram indagados acerca de possibilidade de as coordenações dotarem os futuros universitários de maior grau de informação sobre os cursos. A maioria dos docentes $(81,1 \%)$ afirmou que essas informações devem ser divulgadas pelas coordenações. Entretanto 9,43\% não concordam que essa função seja de responsabilidade das mesmas. Dos que foram favoráveis, 48,8\% sugeriram que essas informações poderiam ser divulgadas aos estudantes por meio de seminários, disciplinas introdutórias, palestras, e outros eventos; $18,6 \%$ através de visitas às escolas de ensino médio, públicas e privadas; 13,8\% a partir de trabalho coletivo entre coordenações, docentes, Pró-Reitorias, Clínica de Psicologia, Serviço Social e Ouvidoria; por fim, $9,2 \%$ crêem que através da participação de vestibulandos às instalações da UFC e da divulgação, pela Internet (UNIVERSIDADE FEDERAL DO CEARÁ, 2006) e por folhetos distribuídos no período das inscrições para - vestibular. Dentre os docentes desfavoráveis, $80 \%$ alegaram que a responsabilidade de divulgar essas informações é das escolas e não das coordenações dos cursos de graduação da UFC.
Acerca do envolvimento docente no ensino de graduação, as seguintes opiniões emanaram do discurso dos partícipes da pesquisa:

- Para 52,9\% dos professores é satisfatório. Deste grupo, 55,5\% ressaltaram que há muito interesse por parte de todos em ensinar e manter a qualidade do ensino, porém 14,8\% afirmaram que há envolvimento de significativa parcela de professores substitutos é péssimo;

- De acordo com 23,5\% é insatisfatório, pois na opinião de $41,6 \%$ deles, a prioridade é dada, de modo acentuado, ao ensino de pós-graduação e ao desenvolvimento de pesquisas;

- Segundo 23,5\% é parcialmente satisfatório, visto que a atuação docente depende muito da motivação pessoal de cada professor, isto é, de aspectos intrínsecos.

Os professores ressaltaram como possíveis ações da UFC visando a combater a evasão discente:

- Melhoria da infra-estrutura física, com especial ênfase às salas de aula e aos laboratórios (citado por 19,04\%);

- Compreensão das causas da evasão discente visando a combatê-la (mencionado por 15,8\%);

- Melhoria da qualidade do ensino e do projeto político pedagógico dos cursos de graduação (destacado por $12,6 \%)$;

- Informação aos vestibulandos acerca de aspectos básicos dos cursos de graduação, em consonância com o que propõe Andriola (2004) e Andriola, Ribeiro e Moura (2005), além do aumento da oferta de cursos noturnos (enfatizado por 10,1\%). 
Destacaram as possíveis ações sob a responsabilidade das coordenações:

- Promover seminários destinados aos egressos do ensino médio, com vistas a informá-los acerca dos cursos, das carreiras profissionais, dos eventos acadêmico-científicos, dos estágios, da pós-graduação e de bolsas $(29,9 \%)$;

- Acompanhar e orientar os discentes de modo sistemático e institucionalizado (apontado por 28,3\%);

- Flexibilizar a grade curricular, rever critérios de pré-requisito, viabilizar decisões colegiadas nas coordenações, cobrar dos docentes maior comprometimento com o ensino (mencionado por 10\%).

Finalmente, os docentes opinaram acerca das ações que eles próprios podem levar a cabo e que resultariam no combate à evasão discente:

- Acompanhar, orientar e incentivar os discentes durante toda a vida acadêmica (mencionado por expressivos 47,5\%);

- Melhorar sua formação e exercer a contento seu papel de educador (destacado por 16,3\%);

- Tornar as aulas mais interessantes e unir teoria e prática (enfatizado por 9,8\%);

- Melhorar a avaliação do desempenho dos alunos; incrementar o combate às dificuldades de aprendizagem; apoiar as iniciativas das coordenações por mais investimentos para as bibliotecas e para a aquisição de equipamentos didáticos (proposto por 6,5\%).

Entretanto, 4,9\% dos docentes afirmaram que o número reduzido de professores engajados institucionalmente e a falta de recursos materiais são, ambos, fatores que impossibilitam e/ou dificultam realizar algumas dessas atividades.

A incompatibilidade entre os horários de trabalho e de estudo foi um aspecto apontado por quase $40 \%$ dos evadidos como sendo causa relevante causa do abandono, conforme sugerem os resultados da pesquisa executada por Andriola, Ribeiro e Moura (2005). Para solucionar esse grave empecilho educacional os professores sugeriram:

- Maior flexibilização de horários de disciplinas, objetivando disponibilizar tempo para os alunos que necessitam trabalhar (mencionado por 39\%);

- Aumentar a oferta de cursos noturnos (destacado por 18,5\%);

- Aumentar a oferta de bolsas (de pesquisa, de extensão, de assistência e de monitoria) e de estágios remunerados (citado por 14,06\%).

\section{À Guisa de Conclusões e de Encaminhamentos}

$O$ primeiro aspecto relevante que deve ser ressaltado a partir da investigação refere-se ao seguinte dado: a maioria dos coordenadores (87\%) e dos docentes (74\%) entrevistados tem opinião favorável ao resgate da função do professor orientador, no âmbito interno da UFC. Entretanto, esse mesmo contingente destaca ser imprescindível a preparação do corpo docente, a disponibilidade de tempo para a execução dessa atividade e a existência de recursos materiais adequados a tal.

Ambos os agentes institucionais (docentes e coordenadores) ressaltaram que cabe 
às coordenações fornecer informações pertinentes e relevantes a todos os potenciais candidatos aos cursos da UFC. Entretanto houve uma minoria discordante que não concorda no exercício dessa função por parte das coordenações. Tais informações poderiam ser divulgadas aos estudantes por meio de variedade de atividades: seminários, disciplinas introdutórias, palestras, visitas dos vestibulandos às instalações da UFC, trabalho coletivo entre as coordenações e as Pró-Reitorias de Graduação e de Assuntos Estudantis, etc.

Indagados acerca do papel da administração central na efetivação de ações institucionais de combate à evasão, opinaram, majoritariamente, que caberá ao gestor dar ênfase à melhoria da infra-estrutura física, com especial atenção às salas de aula e aos laboratórios. Também crêem que os resultados da investigação possibilitarão às Pró-Reitorias de Planejamento, Graduação, de Assuntos Estudantis e de Extensão, em consonância com a Gestão Central da UFC, pensarem, conjuntamente, em implementar políticas institucionais internas factíveis e efetivas no combate à evasão discente dos cursos de graduação.

Fundamentados no modelo causal testado nesse estudo, expressaremos um suposto básico: a tarefa mais relevante que uma IES pública deve prestar à sociedade e, principalmente, aos setores socialmente menos favorecidos - os egressos do ensino médio oriundos de escolas públicas fazem parte desse segmento - é propiciar informações adequadas acerca dos serviços que oferece e das atividades que executa. Sobretudo quando essa IES se encontra num contexto social extremamente desfavorável, conforme expressam os indicadores sociais, educaci- onais e econômicos utilizados no modelo de Andriola, Ribeiro e Moura (2005).

Como a variável "grau de informações acerca do curso abandonado" é a que demonstrou ter maior poder preditivo para explicar a intenção de voltar a cursar uma carreira superior, necessário faz-se a implementação de ações institucionais para enriquecer as informações dos egressos do ensino médio acerca dos cursos e carreiras universitárias oferecidas pela UFC. Desse modo, poderíamos imaginar a criação de um Serviço de Orientação e Informação (SOI) destinado aos egressos do ensino médio, futuros candidatos aos cursos de graduação da UFC, conforme a proposta de Andriola (2003ac).

Mencione-se, ademais de implantação do SOI, a necessidade de discutirmos a possibilidade de resgatarmos a função do Professor Orientador, conforme estabelece o Regimento Geral da UFC, em seu artigo 28, alínea $d$. Os aprendizes universitários já matriculados deverão ter um acompanhamento mais sistemático, tanto por parte das Coordenações de Cursos quanto pelas Pró-Reitorias de Graduação e Assuntos Estudantis. Objetivo central desse acompanhamento será combater o "represamento", as reprovações e as evasões (BOSI, 2000; FERNANDES, 2001). Pensamos ser relevante retomar a idéia de orientar os alunos que demonstrem dificuldades no processo de ensino e aprendizado (BRAGA, MIRANDA-PINTO; CARDEAL, 1996). Aliás, essa é uma atividade existente em algumas IES, como é o caso da Universidade Estadual Paulista (UNESP). Nessa IES, no curso de Matemática, nos campus de Rio Claro e São José do Rio Preto, foi implantado um programa de acompanhamento 
dos calouros cujo objetivo é recuperar conteúdos básicos do ensino médio para, com isto, aperfeiçoar o seu nível de aprendizagem e combater novas reprovações e evasões, conforme asseveram D'Ambrosio (1997), Lotufo e outros (1997, 1998), Paredes (1994) e Ramos (1995, 1998).

Com os calouros, isto é, com os recémingressantes, poderemos vir a trabalhar os seguintes aspectos: criação de um clima amistoso e cooperativo; integração de estudantes dos mais variados cursos; aumento da reflexão crítica e da consciência coletiva; incremento de informações sobre a UFC, por exemplo: atividades acadêmicas oferecidas no âmbito do curso ou da IES (investigação, extensão, monitorias, congressos científicos, etc); trabalho individualizado com os calouros que tenham pro- blemas acadêmicos resultantes da escolha equivocada do curso ${ }^{7}$.

Convém fazer constância de que é desejo nosso converter o $\mathrm{SOl}$ em atividade de referência para a sociedade cearense, reconhecido por tal e, sobretudo, pelos seus usuários: os egressos do ensino médio, candidatos aos cursos da UFC. Isso poderá converter-se em dividendos para a UFC, pois a sociedade verá a preocupação da instituição em oferecer novos serviços, de real utilidade e valor sociais (ANDRIOLA; McDONALD, 2003, 2004). Esse é um dos nossos sonhos. Por falar em sonhos, concluiremos com uma das célebres frases do compositor baiano Raul Seixas, que em certa ocasião asseverou: "sonho que se sonha só é só um sonho. Sonho que se sonha junto é realidade".

\section{Referências}

AMARAL, N. C. A universidade pública no Brasil: identidade e projeto institucional em questão. In: TRINDADE, H. (Org.). Universidade em ruínas na república dos professores. Petrópolis: Vozes, 1999.

ANDRIOLA, W. B. Avaliação do raciocínio verbal em estudantes do $2^{\circ}$ grau. Estudos de Psicologia, Natal, RN, v. 2, n. 2, p. 277-285, 1997 b.

Avaliação institucional na Universidade Federal do Ceará (UFC): organização de sistema de dados e indicadores da qualidade institucional. Avaliação: revista da Rede de Avaliação Institucional da Educação Superior, Campinas, v. 9, n. 4, p. 33-54, 2004.

Cuidados na avaliação da aprendizagem: algumas reflexões. In: McDONALD, B. C. (Org.). Esboços em avaliação educacional. Fortaleza: Ed. da Universidade Federal do Ceará, 2003b.

. Evasão discente na Universidade Federal do Ceará (UFC): proposta para identificar suas causas e implantar um Serviço de Orientação e Informação (SOI). Ensaio: avaliação de políticas públicas em educação: revista da Fundação Cesgranrio, Rio de Janeiro, v. 11, n. 40, p. 332-347, 2003c.

${ }^{7}$ Ver Andriola (1997a, 1997b, 2003a, 2003b, 2003c). 
ANDRIOLA, W. B. Evasão discente no âmbito da Universidade Federal do Ceará (UFC): proposta para identificar suas causas e implantar um Serviço de Orientação e Informação (SOI) para os egressos do ensino médio. In: ENCONTRO DE PESQUISA EDUCACIONAL DO NORTE E NORDESTE, 16., 2003, São Cristóvão. Anais... São Cristóvão: Universidade Federal de Sergipe, 2003a. p. 483.

Expectativas de estudantes do $2^{\circ}$ grau sobre a Universidade. Educação em Debate, Fortaleza, n. 33, p. 39-45, 1997a.

ANDRIOLA, W. B. (Org.). Avaliação: múltiplos olhares em torno da educação. Fortaleza: Editora da Universidade Federal do Ceará, 2005.

ANDRIOLA, W. B.; McDONALD, B. C. (Org.). Avaliação: Fiat Lux em educação. Fortaleza: Editora da Universidade Federal do Ceará, 2003.

Avaliação educacional: navegar é preciso. Fortaleza: Ed. da Universidade

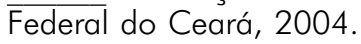

ANDRIOLA, W. B.; RIBEIRO, E. S. Evasão discente nos cursos de graduação da UFC: proposta de modelo explicativo de suas causas. In: ENCONTRO DE PESQUISA EDUCACIONAL DO NORTE-NORDESTE, 17., 2005, Belém. Anais ... Belém, PA: Ed. Universidade Federal do Pará, 2005.

ANDRIOLA, B. A.; RIBEIRO, E. S.; MOURA, C. P. Evasão discente nos cursos de graduação da Universidade Federal do Ceará (UFC): busca das suas causas . In: ANDRIÓLA, W. B. (Org.). Avaliação: múltiplos olhares em educação. Fortaleza: Ed. da Universidade Federal do Ceará, 2005.

BEAN, J. P. The application of a model of turnover in work organizations to the student attrition process. Review of Higher Education, New York, n. 6, p. 129-148, 1983.

Dropouts and turnover: the synthesis and test of a causal model of student attrition. Research in Higher Education, Baltimore, v. 12, n. 2, p. 155-187, 1980.

BEAN, J. P.; METZNER, B. S. A conceptual model of nontraditional undergraduate student attrition. Review of Educational Research, New York, v. 55, n. 4, p. 485-540, 1985.

BOSI, A. A importância da universidade pública. Ciência Hoje, São Paulo, v. 28, n. 165, p. 42-48, 2000.

BRAGA, M. M.; MIRANDA-PINTO, C. O. B.; CARDEAL, Z. L. Perfil sócio-econômico dos alunos, repetência e evasão no curso de química da UFMG. São Paulo: Núcleo de Pesquisa sobre Ensino Superior da Universidade de São Paulo, 1996. Documento de Trabalho NUPES, 5/96.

CABRERA, A. F. et al. The convergence between two theories of college persistence. Journal of Higher Education, New York, v. 63, n. 2, p. 143-164, 1992.

CASTRO, C. M. Educação. Brasília, DF, [200-?]. Disponível em: <http:// www.mre.gov.br/cdbrasil/itamaraty/web/port/polsoc/educa/apresent/apresent.htm $>$. Acesso em: 29 set. 2006. 
COL DEBELLA, M. A. Efeitos do primeiro semestre curricular sobre a mudança de atitudes do aluno em relação à universidade. 1978. Dissertação (Mestrado)Universidade Federal da Paraíba, João Pessoa, 1978.

CUNHA, A. M.; TUNES, E.; SILVA, R. R. Evasão do curso de química da Universidade de Brasília: a interpretação do aluno evadido. Química Nova, São Paulo, v. 24, n. 1, p. 262-280, 2001 .

D'AMBROSIO, O. Os problemas da matemática que não são numéricos. Jornal da UNESP, São Paulo, ano 12, n. 114, jun. 1997.

DURHAM, E. R. Uma proposta para o ensino superior brasileiro: diagnóstico e proposta. São Paulo: Núcleo de Pesquisa sobre o Ensino Superior da Universidade de São Paulo, 1998. Documento de trabalho NUPES, 3/98.

. As universidades públicas e a pesquisa no Brasil: relatório técnico apresentado ao CEBRAP/NUPES. São Paulo: Núcleo de Pesquisa sobre o Ensino Superior da Universidade de São Paulo, 1999.

FERNANDES, T. Educação com qualidade. Ciência Hoje, São Paulo, v. 30, n. 176, p. 56-58, 2001.

GOUVEIA, V. V.; ALBUQUERQUE, F. J. B.; SOLHA, A. C. Expectativas da comunidade frente à universidade. Revista de Psicologia, Fortaleza, CE, v. 11/12, n. 1/2, p. 5-18, 1994.

INSTITUTO NACIONAL DE ESTUDOS E PESQUISAS EDUCACIONAIS. Resultados e tendências da educação superior no Brasil. Brasília, DF, 2000.

LOTUFO, A. D. et al. A evasão e repetência escolar relacionadas com a metodologia de ensino. In: CONGRESSO BRASILEIRO DE ENSINO DE ENGENHARIA, 25., 1997, Salvador. Anais... Salvador: COBENGE, 1997. p. 2148-2160.

. Evasão e repetência na FEIS/UNESP: análise e resultado. In: CONGRESSO BRASILEIRO DE ENSINO DE ENGENHARIA, 26., 1998, São Paulo. Anais... São Paulo: COBENGE, 1998. p. 185-203.

NORA, A.; CASTANEDA, M. B.; CABRERA, A. F. Student persistence: the test of a comprehensive structural model of retention. In: ASHE ANNUAL MEETING, 1992, Minneapolis. Paper presented... Minneapolis, Minnesota: Association for the Study of Higher Education, 1992.

PACHECO, E.; RISTOFF, D. Educação superior: democratizando o acesso. Brasília, DF: INEP, 2004. (Série textos para discussão, n. 12).

PAREDES, A. S. A evasão do terceiro grau em Curitiba. São Paulo: Núcleo de Pesquisa sobre Ensino Superior da Universidade de São Paulo, 1994. Documento de Trabalho NUPES, 6/94. 
PUENTE VIEDMA, C. SPSS/PC+ ${ }^{+}$una guía para la investigación. Madrid: Editorial Complutense, 1993.

RAMOS, M. N. Quadro de evasão na UFPE: metodologia, causas e ações. Recife: Universidade Federal de Pernambuco, 1995.

. Vestibular e evasão. Jornal do Commercio, Recife, 29 set. 1998.

RIBEIRO, C. As causas da evasão universitária. In: ENCONTRO SETORIAL DOS CURSOS DE GRADUAÇÃO DA UNESP, 1., 1995, Águas de Lindóia. Anais... Águas de Lindóia, SP, 1995. p. 10-12.

RIBEIRO, E. S.; MOURA, C. P.; ANDRIOLA, W. B. Evasão discente na Universidade Federal do Ceará: dados relativos aos anos 1999-2000. In: ENCONTRO DE INICIAÇÃO CIENTÍFICA E TECNOLÓGICA DO CENTRO FEDERAL DE EDUCAÇÃO TECNOLÓGICA (CEFET/CE), 3., 2003, Fortaleza. Anais... Fortaleza, 2003.

SCHWARTZMAN, S. O ensino superior no Brasil. Brasília, DF: Instituto Nacional de Estudos e Pesquisas Educacionais, 1999.

SOBRINHO, J. D. Avaliação da educação superior. Petrópolis: Editora Vozes, 2000.

STOECKER, J.; PASCARELLA, E. T.; WOLFLE, L. M. Persistence in higher education: a 9year test of a theoretical model. Journal of College Student Development, New York, n. 29, p. 196-209, 1988.

TINTO, V. Dropout from higher education: a theoretical synthesis of recent research. Review of Educational Research, New York, n. 45, p. 89-125, 1975.

TINTO, V. Leaving college: rethinking the causes of student attrition. Chicago, III.: University of Chicago Press, 1987.

UNESCO. Gender-sensitive education statistics and indicators: a practical guide. New York, 1997.

UNIVERSIDADE FEDERAL DO CEARÁ. Comissão Coordenadora do Vestibular. Vestibular 2000. Fortaleza, CE, 1999. Disponível em: <http://www.ccv.ufc.br/vestib00.php>. Acesso em: 5 out. 2006.

UNIVERSIDADE FEDERAL DO CEARÁ. Coordenadoria de Concursos. Página principal da CCV. Fortaleza, CE, 2006. Disponível em: <http://www.ccv.ufc.br>. Acesso em: 5 out. 2006.

UNIVERSIDADE FEDERAL DO CEARÁ. Pró-Reitoria de Planejamento. Avaliação institucional da Universidade Federal do Ceará: análise crítica dos dados e recomendações: relatório técnico. Fortaleza, CE: Ed. da UFC, 2001.

Recebido em: 31/03/2006

Aceito para publicação em: 26/06/2006 